\section{Concepções sobre inovação no jornalismo: tendências nas pesquisas entre 2017 e 2019}

\author{
Laura Strelow Storch \\ Bruna Eduarda Meinen Feil
}

\section{Resumo:}

O presente estudo tem como objetivo apresentar um mapeamento do estado da arte sobre inovação e Jornalismo, considerando as pesquisas desenvolvidas entre 2017 e 2019. O recorte analítico foi realizado a partir de duas estratégias centrais: a busca manual em bases de dados brasileiras e a busca automatizada em indexadores internacionais - CrossRef e Google Acadêmico. O corpus consolidado da pesquisa é de 125 trabalhos, que foram classificados em cinco categorias: concepções de inovação, inovação de gestão, inovação de processo, inovação de produto, agentes de inovação. Entre os principais resultados, destacamos a fragmentação da produção entre múltiplos autores e em distintas publicações e a variedade de assuntos enquadrados pelos pesquisadores como parte do debate sobre inovação no contexto jornalístico.

Palavras-chave: Jornalismo. Inovação. Conceito. Estado da Arte.

State of the art on journalism and innovation: trends in research between 2017 and 2019

\begin{abstract}
:
This paper aims to present an analysis of the state of the art on innovation and journalism, considering the research developed between 2017 and 2019. The analytical approach was carried out based on two central strategies: the manual search in Brazilian databases and the automated search in international indexers - CrossRef and Google Scholar. The consolidated corpus of the research consists of 125 works, which were classified into five categories: conceptions of innovation, management innovation, process innovation, product innovation, innovation agents. Among the main results, the fragmentation of production between multiple authors and in various publications and the variety of subjects framed by researchers as part of the debate on innovation in the journalistic context.
\end{abstract}

Keywords: Journalism. Innovation. Concept. State of the art.
Recebido em: 08.07.20

Aprovado em: 24.02.21

\section{Laura Strelow Storch \\ Jornalista, doutora em Comunicação e Informa- ção (UFRGS), professora adjunta no Departa- mento de Ciências da Comunicação (UFSM) e docente no PPG em Co- municação (UFSM). Co- ordenadora do Labora- tório de Experimentação em Jornalismo (LEx-U- FSM) e vice-coordenado- ra do Grupo de Pesquisa Estudos de Jornalismo (CNPq/UFSM).}

E-mail: 1sstorch@gmail. com

\section{Bruna Eduarda Meinen Feil}

Acadêmica do $7^{\circ}$ semestre do curso de Comunicação Social - Habilitação Jornalismo (UFSM) e bolsista de iniciação científica no Laboratório de Experimentação em Jornalismo (LEx-UFSM).

E-mail: brunameinen@ gmail.com 
discussão sobre inovação é recente no campo de estudos em Jornalismo, resultado de uma diversidade de experiências teóricas e empíricas que delimitaram, nas últimas décadas, movimentos de transformação do campo profissional - imbricadas em condicionamentos institucionais, organizacionais, técnicos e tecnológicos, éticos e deontológicos. A emergência e as transformações de um conceito, em um campo determinado, resultam da interação entre a sua história semântica e seus horizontes de adequação a sistemas político-sociais determinados. Como nos lembra Koselleck (2006), acionar uma palavra como conceito é adicionar à investigação do campo de conhecimento uma unidade de significado que projeta ação política. É neste contexto que nos aproximamos do debate sobre inovação no jornalismo.

Longhi e Flores (2017, p. 24) acreditam que o debate sobre inovação vem enfrentando situação semelhante à ocorrida com o conceito de "convergência", ou seja, seu uso é abrangente, "[...] aplicável a inúmeras situações e áreas do conhecimento", de modo a descrever uma variedade de fenômenos não necessariamente relacionados. As pesquisadoras alertam para a importância de delinear contornos teóricos e espelhar o sentido do termo inovação e suas implicações práticas no campo jornalístico. Justamente por ser examinada a partir de distintas tradições de investigação, torna-se difícil acompanhar e mapear a discussão sobre inovação.

Um conceito é sempre polissêmico, mas essa polissemia está circunscrita por uma totalidade - pelas circunstâncias de historicidade, por sua inscrição em um tempo e contexto determinados que, necessariamente, se agregam a ela. É nesse sentido que Rodrigues (2020, p. 156) defende a necessidade de compreensão de um conceito de forma sempre relacional, “[...] sempre hermeneuticamente, sempre em coadjuvância com o contexto teórico e empírico”. Neste trabalho, temos como objetivo a investigação sobre o estado da arte da pesquisa sobre inovação no jornalismo, buscando reconhecer os pesquisadores e publicações que têm se dedicado a promover o debate da inovação neste campo de estudos, bem como quais são as problematizações que vêm sendo feitas por estes atores.

Nossa análise levou em consideração bases de dados brasileiras e indexadores internacionais, no período entre 2017 e 2019, e se concentrou em um corpus consolidado de 125 pesquisas. O recorte foi operado a partir de um desenho metodológico que tem por objetivo explorar elementos emergentes do conceito de inovação nas pesquisas em jornalismo. Essa decisão limita os resultados da análise porque ignora pesquisas que discutam processos de inovação sem efetivamente utilizar o conceito. Apesar disso, favorece a observação acerca da adoção do conceito de inovação no campo do jornalismo e do debate atual sobre inovação neste campo específico. A investigação qualitativa considerou a leitura exploratória dos títulos, palavras-chave e resumos de todos os trabalhos que compõem o corpus consolidado da análise. Fizemos uma classificação dos trabalhos a partir dos objetivos descritos pelos autores e chegamos em um total de cinco categorias gerais: concepções de inovação, inovação de gestão, inovação de processo, inovação de produto, agentes de inovação.

\section{Inovação e Jornalismo}

O início das reflexões sobre inovação é comumente atribuído aos trabalhos do economista e cientista político Joseph Schumpeter. De acordo com o autor, o objetivo principal da inovação é obter maior lucratividade nas organizações, sendo ela o principal mecanismo através do qual o capitalismo se desenvolve (SCHUMPETER, 1985). Em sua quarta e mais recente edição, lançada em 2018, o Manual de Oslo define inovação como "um produto ou processo novo ou melhorado (ou 
uma combinação deles) que difere significativamente dos produtos ou processos anteriores da unidade e que foi disponibilizado a usuários em potencial (produto) ou colocados em uso pela unidade (processo)" (OECD/EUROSTAT, 2018, p. 20, tradução nossa ${ }^{1}$ ).

No Jornalismo, Grohmann (2016) acredita que há uma idealização do termo inovação, visto que pequenas modificações, seja no produto final ou em seus processos de elaboração, são alardeadas como inovação. Para o autor, essa banalização do termo seria preocupante. "Além disso, se tudo pode ser considerado 'inovador', o que é realmente 'inovador'? Qual o poder explicativo do termo?" (GROHMANN, 2017, p. 4). Já Creech e Nadler (2017) definem a inovação como sendo um conceito escorregadio, que predominantemente vai permear mudanças técnicas relacionadas ao âmbito dos processos de produção e distribuição das notícias, bem como dos modelos de financiamento para as empresas.

Alguns autores da área se propõem a estudar a inovação tendo como pano de fundo a discussão sobre uma suposta crise vivenciada pelo jornalismo (SAAD, 2016; TAVARES, 2017). No jornalismo, além de afetar o modelo de negócio e a sustentabilidade do ponto de vista econômico, a crise também perpassa os valores e a identidade da profissão (PEREIRA; ADGHIRNI, 2011; GROHMANN e ROXO, 2015). Tendo em vista esse cenário, Bittencourt (2018) aponta que a inovação passa a ser considerada como uma rota de fuga desse quadro problemático:

\begin{abstract}
A inovação ao mesmo tempo em que abre novas oportunidades de modificação do produto jornalístico para acompanhar o progresso tecnológico provoca a remodelação de processos e modelos que já não mais funcionam dentro de um mercado onde a geração de receita baseada na venda de publicidade não é mais suficiente para sustentar uma empresa jornalística (BITTENCOURT, 2018, p. 77).
\end{abstract}

Corroborando com essa perspectiva, Longhi e Flores (2017) acreditam que a inovação é uma reação ligada a alguma insatisfação, ainda que jamais deva ser entendida como uma mera solução de problemas. As autoras salientam que, em função da constância das transformações tecnológicas e do comportamento do mercado consumidor de notícias, "a inovação não pode ser vista como um elemento extra, e sim como uma necessidade para a área, que busca alternativas para sobreviver em um cenário de crise" (LONGHI; FLORES, 2017, p. 24-25).

Bittencourt (2018) nos lembra que a mera ocorrência do desenvolvimento tecnológico ou adoção de tecnologia não é o suficiente para garantir a inovação. Franciscato (2010) compartilha desse mesmo entendimento e avalia que uma dimensão mais complexa da ideia de inovação exige "considerar três vertentes deste fenômeno (tecnológica, organizacional e social), para, assim, possibilitar uma maior densidade conceitual e superar um viés excessivamente tecnológico em suas abordagens" (FRANCISCATO, 2010, p. 9).

Diversos autores têm se dedicado a estudar como, de fato, tem ocorrido o processo de inovação nas organizações jornalísticas. Em nossas leituras, conseguimos identificar três principais tendências que vêm sendo descritas pelos pesquisadores do campo, são elas: inovações organizacionais, inovações de produto e inovações de processo.

O primeiro eixo, que trata das inovações organizacionais, está relacionado ao desenvolvimento de novos modelos de negócio e estratégias de sustentabilidade financeira para organizações jornalísticas, visto que o modelo tradicional de financiamento do jornalismo, baseado na geração de receita através da venda de assinaturas e publicidade, tem sido apontado como insuficiente para viabilizar a estrutura das redações. Esse tipo de jornalismo industrial, mainstream, baseado no modelo americano (DE MATEO, BERGÉS \& GARNATXE, 2010) foi central até o início da década de 1990, quando ocorre a entrada massiva de computadores nas redações e a popularização da internet comercial, que começa a atender finalidades jornalísticas.
${ }^{1}$ No original: "An innovation is a new or improved product or process (or combination thereof) that differs significantly from the unit's previous products or processes and that has been made available to potential users (product) or brought into use by the unit (process)". (OECD/EUROSTAT, 2018, p. 20).). 
De acordo com Pereira e Adghirni (2011), a partir de então, esse modelo começa a apresentar sinais de esgotamento porque as receitas das mídias convencionais começam a cair devido à redução no número de leitores, pela falta de credibilidade $\mathrm{e}$ pela migração da publicidade para a web. Com isso, o vínculo entre as audiências e o jornalismo tornou-se instável, pois, diariamente, o indivíduo pode optar por renovar ou não a relação que possui com um veículo de comunicação (FRANCISCATO, 2005). Esse processo provoca uma fragmentação do consumo, o que exige que as empresas desenvolvam novos modelos e estratégias para captar os leitores.

Mas, transformações que a internet provocou no âmbito organizacional, também podem ser percebidas quando pensamos nos produtos jornalísticos, sobre os quais a literatura tem descrito o surgimento de formatos e linguagens como os webdocumentários, newsgames, infografias interativas, textos no formato longform e o uso de realidade virtual nas narrativas imersivas - citados como exemplos de inovações desenvolvidas a partir da estruturação convergente da internet. Essas novas narrativas impactam de forma expressiva os processos produtivos do jornalismo. Ao se referir especificamente à estrutura de produção jornalística, Franciscato (2014) aponta que, na contemporaneidade, novas rotinas de trabalho são desenhadas para as organizações jornalísticas, tendo como foco a concepção de integração e convergência dos ambientes de trabalho.

Para Salaverría (2003), há quatro dimensões da convergência - empresarial, tecnológica, comunicativa e profissional - que denotam utilização da internet nas rotinas produtivas; avanço tecnológico nas redações; mudanças no discurso informativo e novas atribuições dos jornalistas. Adghirni (2012) acredita que as características da internet desconfiguram o modo tradicional de produzir e impõe uma carga de trabalho ininterrupta aos jornalistas. Essa carga de trabalho sobre qual fala a autora é passível de ser compreendida se pensarmos na necessidade que os jornalistas têm de vencer a concorrência em tempo, ineditismo e quantidade de material produzido, além de informar o leitor conectado à internet por múltiplas plataformas.

Uma das mudanças provocadas pela convergência das redações e que tem impacto nos processos produtivos do jornalismo diz respeito aos novos atores, como por exemplo designers e programadores, que passam a participar de forma decisiva do processo de produção jornalística. Esses agentes são chamados pelos teóricos de "intrusos" (interlopers) (ELDRIDGE, 2018; HOLTON, BELAIR-GAGNON, 2018) ou "tecnoatores" (CANAVILHAS et al, 2016). Além disso, o avanço da Inteligência Artificial possibilitou o desenvolvimento de algoritmos capazes de redigir notícias em uma velocidade muito superior ao trabalho que qualquer repórter ou editor humano seria capaz de realizar (COSTA, 2016).

Neste novo ecossistema midiático que emerge do assim chamado ambiente pós-industrial (ANDERSON, BELL, SHIRKY, 2012), o jornalismo deve encontrar seu espaço "não apenas entre novas organizações nativas digitais, mais ágeis e prontas para a inovação, e um público anteriormente conhecimento [sic] como a audiência ávido por participar e produzir conteúdo; mas também entre atores humanos e não-humanos" (COSTA, 2016, p.2). Considerando o cenário teórico exposto, compreendemos que é importante acompanhar de forma sistematizada as produções acadêmicas sobre inovação no jornalismo, de modo a reconhecer os eixos de fundamentação e os modos de consolidação do conceito como objeto de investigação científica.

\section{Arquitetura metodológica}

O período selecionado para a coleta de dados foi de três anos, entre 2017 e 2019. A coleta foi realizada a partir de duas estratégias principais: a) busca manual nas bases de dados brasileiras - Catálogo de Teses e Dissertações da Capes, Anais dos Encontros Nacionais da Associação Brasileira de Programas de Pós-Gradua- 
ção em Comunicação (Compós) e Anais dos Encontros da Associação Nacional de Pesquisadores em Jornalismo (SBPJor); b) busca automatizada, com o apoio do software de recuperação e análise de citações acadêmicas "Publish or Perish", nos indexadores CrossRef e Google Acadêmico. Neste caso, foram feitas buscas em português e inglês.

A busca na base de dados da Capes foi feita a partir dos seguintes critérios: a) Grande Área do Conhecimento: Ciências Sociais Aplicadas, b) Área do Conhecimento: Comunicação / Comunicação e Informação, e c) palavras-chave "jornalismo" e "inovação". Foram feitas buscas individuais, a partir das mesmas categorias, para trabalhos catalogados como "teses", "dissertações" e "doutorado e mestrado profissional". No caso dos Anais da Compós, as pesquisas foram realizadas a partir do endereço eletrônico www.compos.org.br/anais_encontros.php, onde foram selecionados os eventos de 2017, 2018 e 2019. Para cada um deles, utilizamos a ferramenta de busca oferecida pela entidade - que realiza as buscas nos títulos dos trabalhos e no campo destinado ao registro dos autores. Utilizamos o termo de pesquisa "inovação". Nenhum trabalho aprovado para apresentação nos 20 grupos de trabalho da Compós nestes três anos continha a palavra inovação em seu título. No caso dos Encontros da SBPJor, a busca foi realizada através da ferramenta de buscas do Sistema de Conferências da SBPJor. Selecionamos individualmente os Anais dos Encontros de 2017, 2018 e 2019 e, em cada um deles, realizamos a pesquisa de títulos (a outra opção disponível para busca é do registro de autores) a partir do termo "inovação".

Tabela 1: Busca manual de trabalhos sobre inovação nas bases de dados brasileiras selecionadas.

\begin{tabular}{|c|c|c|c|c|}
\hline $\begin{array}{c}\text { Tipo de } \\
\text { busca }\end{array}$ & Base de Dados & Ano Base & $\begin{array}{c}\text { Total de tra- } \\
\text { balhos recu- } \\
\text { perados }\end{array}$ & $\begin{array}{c}\text { Total } \\
\text { consolidado }\end{array}$ \\
\hline Manual & CAPES - teses & $2017-2019$ & 124 & 5 \\
\hline Manual & CAPES - dissertações & $2017-2019$ & 375 & 6 \\
\hline Manual & CAPES - M/D profissionais & $2017-2019$ & 40 & 4 \\
\hline Manual & Anais Compós & $2017-2019$ & 0 & 0 \\
\hline Manual & Anais SBPJor & $2017-2019$ & 18 & 15 \\
\hline & & TOTAL & $\mathbf{5 5 7}$ & $\mathbf{3 0}$ \\
\hline
\end{tabular}

Fonte: as autoras.

Com o total de 557 trabalhos recuperados com essas buscas, organizamos uma planilha para análise e classificação qualitativa dos dados. A planilha foi organizada com os seguintes dados: origem (base de dados de onde o dado foi extraído), autor, título, PPG/Anais, editor (universidade, editor ou entidade promotora do evento) e URL (o endereço eletrônico para acesso ao arquivo). Cada um dos trabalhos foi verificado qualitativamente. Buscamos referências sobre a relação temática entre jornalismo e inovação nos títulos, nas palavras-chave e nos resumos de cada um dos trabalhos, filtrando apenas aqueles que correspondiam aos interesses desta investigação. Foram excluídos trabalhos que não diziam respeito ao jornalismo e aqueles que, ainda que fizessem menção a temas correlacionados, não tinham como foco o conceito de inovação (por exemplo, trabalhos que tematizam as métricas como recurso para a produção de notícias, mas não vinculam esse fenômeno como um tipo de inovação do campo profissional). Depois da análise qualitativa dos trabalhos, obtivemos um corpus consolidado de 30 trabalhos, apenas 5,4\% do total.

A busca automatizada, com o auxílio de software, foi realizada a partir dos seguintes parâmetros: a) palavras-chave “jornalismo" e "inovação", b) pesquisa 
individual para palavras-chave em português e inglês, c) limite de 200 registros por pesquisa, d) pesquisa individual por ano (2017, 2018 e 2019). Por conta dessa parametrização, foram realizadas um total de 12 buscas, cada uma delas revertendo 200 entradas - num total de 2400 resultados. Como na etapa anterior, todos os resultados foram planificados em uma tabela com os seguintes dados: origem, autor, título, revista, editor e URL. Novamente, cada um dos trabalhos foi verificado qualitativamente, com a busca de referências sobre a relação temática entre jornalismo e inovação nos títulos, nas palavras-chave e nos resumos dos artigos, filtrando apenas aqueles que correspondiam aos interesses desta investigação. Foram excluídos trabalhos que não diziam respeito ao Jornalismo, documentos que representavam resenhas de livros ou citações, documentos que não se caracterizavam como artigo (introduções de dossiês em revistas científicas, listas de correções realizadas pelos editores, entre outros). O resultado desta verificação nos permitiu o reconhecimento de um total de 156 registros, dos quais 46 pelo indexador CrossRef e 110 pelo Google Acadêmico.

Os dados coletados através dos indexadores ainda precisaram passar por uma última filtragem, em que foram eliminados, para a análise qualitativa das pesquisas, as duplicidades, ou seja, textos que apareciam na busca dos dois indexadores foram analisados e apenas uma das entradas foi mantida. Além disso, tanto na busca manual quando na busca automatizada, alguns textos que indicavam a inovação entre os seus elementos-chave, mas que não tratavam do tema a partir de conceitos objetivos, mas apenas contextualmente, também foram eliminados. Por fim, textos que não eram acessíveis no formato ciência aberta ou mesmo com a identificação institucional da universidade foram desconsiderados. Nosso corpus consolidado passou a ser, portanto, de 125 pesquisas.

\section{Análise dos resultados}

Um primeiro movimento de análise realizado foi a observação e o mapeamento dos autores de referência no campo de estudos sobre inovação no jornalismo. Nosso objetivo era verificar a existência de algum nicho de pesquisadores que já pudesse ser visualizado, ainda que o debate sobre inovação seja recente no jornalismo. Fizemos uma filtragem entre os autores, anotando aqueles que apareciam de forma mais recorrente (com maior produção sobre o tema). Nesta etapa não fizemos mais uma diferenciação entre autores brasileiros e estrangeiros. Dos três pesquisadores mais destacados, duas são brasileiras. Cárlida Emerim (UFSC) tem debatido a inovação no contexto do telejornalismo, enquanto a pesquisadora Egle Spinelli (ESPM) tem como foco de seu trabalho a questão da sustentabilidade do negócio jornalístico e das estratégias de inovação em veículos já consolidados. $\mathrm{O}$ espanhol José Alberto García-Avilés, pesquisador na Universidad Miguel Hernández, tem conduzido pesquisas com o foco na discussão sobre inovação no jornalismo. É dele, por exemplo, um conjunto de trabalhos (que descreveremos com mais detalhes adiante) que buscam consolidar uma matriz para a análise da inovação no jornalismo. 
Tabela 2: Autores com mais produção sobre jornalismo e inovação no período analisado.

\begin{tabular}{|c|c|c|c|}
\hline Pesquisador & Instituição & País & Entradas \\
\hline José Alberto García-Avilés & Universidad Miguel Hernández & Espanha & 5 \\
\hline Egle Müller Spinelli & ESPM & Brasil & 4 \\
\hline Cárlida Emerim & UFSC & Brasil & 3 \\
\hline Ana Marta Moreira Flores & UFSC & Brasil & 2 \\
\hline Beatriz Becker (coautoria) & \multirow{2}{*}{ UFRJ } & \multirow{2}{*}{ Brasil } & \multirow{2}{*}{2} \\
\hline Igor Waltz (coautoria) & & & \\
\hline Elaide Martins & UFPA & Brasil & 2 \\
\hline Jaime Anger & University of Oxford & $\begin{array}{l}\text { Inglater- } \\
\text { ra }\end{array}$ & 2 \\
\hline Jane Singer & University of London & $\begin{array}{l}\text { Inglater- } \\
\text { ra }\end{array}$ & 2 \\
\hline Lucas Vieira de Araújo & UMESP & Brasil & 2 \\
\hline $\begin{array}{c}\text { Paulo Eduardo Lins } \\
\text { Cajazeira }\end{array}$ & UFCA & Brasil & 2 \\
\hline Summer Harlow & University of Houston & EUA & 2 \\
\hline Tamara Witschge & University of Groningen & Holanda & 2 \\
\hline
\end{tabular}

Fonte: as autoras.

A Universidade Federal de Santa Catarina (UFSC) se destaca no contexto brasileiro. Ana Marta Moreira Flores, que recentemente defendeu sua tese de doutoramento (FLORES, 2019), tem colaborado para a ampliação do debate sobre inovação no PPG em Jornalismo da UFSC. A pesquisadora foi orientada pela doutora Raquel Longhi, que coordena o grupo de pesquisa Hipermídia e Linguagem (Nephi-Jor/CNPq). O grupo é composto por um conjunto de pesquisadores dedicados ao estudo de novos formatos e metodologias de aplicação de narrativas hipermídia no jornalismo.

Além de buscar por autores de referência, também nos interessava mapear os periódicos que mais publicaram trabalhos relacionados ao tema. Realizamos uma nova filtragem em busca de periódicos científicos e entidades mais recorrentes em nosso corpus. No contexto internacional, a editora Taylor \& Francis figura entre as de maior destaque, com 17 trabalhos, seguida da SAGE Publications com dez e Routledge com seis. Ao avaliar os trabalhos a nível nacional, entidades como a Associação Brasileira dos Pesquisadores em Jornalismo (SBPJor) e a Sociedade Brasileira de Estudos Interdisciplinares da Comunicação (Intercom) se sobressaem com dez e cinco trabalhos, respectivamente. Em relação às universidades, percebemos um núcleo de pesquisas sobre o tema na Escola Superior de Propaganda e Marketing (ESPM), mais especificamente no programa de Mestrado Profissional em Produção Jornalística e Mercado. Além dessa, a UFSC novamente aparece entre os destaques devido às publicações do Programa de Pós-Graduação em Jornalismo (PPGJOR) e da revista Estudos em Jornalismo e Mídia (EJM). Outras universidades como a Pontifícia Universidade Católica do Rio Grande do Sul (PUC-RS) e a Universidade do Vale do Rio dos Sinos (Unisinos) figuram entre as destacadas. 
Tabela 3: Editores e publicações com destaque na produção sobre jornalismo e inovação no período analisado.

\begin{tabular}{|c|c|c|c|}
\hline Editor & Publicação & Quantidade & Total \\
\hline \multirow{4}{*}{$\begin{array}{l}\text { Taylor \& Francis } \\
\text { Group }\end{array}$} & Journalism studies & 5 & \multirow{4}{*}{17} \\
\hline & American Journalism & 1 & \\
\hline & Digital journalism & 6 & \\
\hline & Journalism Practice & 5 & \\
\hline \multirow{6}{*}{ SAGE Publications } & Convergence & 1 & \multirow{6}{*}{10} \\
\hline & Journalism & 4 & \\
\hline & $\begin{array}{l}\text { Journalism \& Mass Communica- } \\
\text { tion Educator }\end{array}$ & 1 & \\
\hline & $\begin{array}{c}\text { Journalism: Theory, Practice \& } \\
\text { Criticism }\end{array}$ & 2 & \\
\hline & Newspaper Research Journal & 1 & \\
\hline & Media, culture and society & 1 & \\
\hline SBPJor & Anais Congresso SBPJor & 10 & 10 \\
\hline \multirow{5}{*}{ Routledge } & $\begin{array}{l}\text { Media Management and Digital } \\
\text { Transformation }\end{array}$ & 1 & \multirow{5}{*}{6} \\
\hline & Navigating Social Journalism & 1 & \\
\hline & Coleção - Routledge Focus & 2 & \\
\hline & Innovation(s) in photojournalism & 1 & \\
\hline & $\begin{array}{l}\text { Coleção - Routledge Studies in } \\
\text { Science, Technology and Society }\end{array}$ & 1 & \\
\hline ESPM & $\begin{array}{l}\text { Mestrado profissional em produ- } \\
\text { ção jornalística e mercado }\end{array}$ & 6 & 6 \\
\hline Intercom & Anais Congresso Intercom & 5 & 5 \\
\hline \multirow{2}{*}{ UFSC } & $\begin{array}{c}\text { Programa de Pós-graduação em } \\
\text { Jornalismo }\end{array}$ & 4 & \multirow{2}{*}{5} \\
\hline & $\begin{array}{c}\text { Revista Estudos em Jornalismo e } \\
\text { Mídia }\end{array}$ & 1 & \\
\hline $\begin{array}{l}\text { HISIN - História dos } \\
\text { sistemas informativos }\end{array}$ & $\begin{array}{c}\text { Revista Latina de Comunicação } \\
\text { Social }\end{array}$ & 4 & 4 \\
\hline PUC-RS & $\begin{array}{c}\text { Programa de Pós Graduação em } \\
\text { Comunicação Social }\end{array}$ & 3 & 3 \\
\hline \multirow{2}{*}{$\begin{array}{l}\text { Springer International } \\
\text { Publishing }\end{array}$} & $\begin{array}{l}\text { Journal of the Knowledge Eco- } \\
\text { nomy }\end{array}$ & 1 & \multirow{2}{*}{3} \\
\hline & $\begin{array}{c}\text { Studies in Systems, Decision and } \\
\text { Control }\end{array}$ & 2 & \\
\hline \multirow[t]{2}{*}{ Unisinos } & $\begin{array}{l}\text { Anais do Seminário Internacio- } \\
\text { nal de Midiatização e Processos } \\
\text { Sociais }\end{array}$ & 1 & \multirow[t]{2}{*}{3} \\
\hline & $\begin{array}{l}\text { Pós-Graduação em Comunicação } \\
\text { Social }\end{array}$ & 2 & \\
\hline
\end{tabular}

Fonte: as autoras

Outro movimento de análise desenvolvido nesta pesquisa foi o mapeamento qualitativo das pesquisas, que serviu para que pudéssemos reconhecer os principais debates propostos pelos pesquisadores em torno da temática geral da inovação no jornalismo. Após a leitura exploratória dos títulos, palavras-chave e resumos de todos os trabalhos que compõem o corpus consolidado da análise, fizemos uma classificação dos trabalhos a partir dos objetivos descritos pelos autores e chegamos em um total de 
cinco categorias gerais: concepções de inovação (33 registros), inovação de gestão (44 registros), inovação de processo (16 registros), inovação de produto (17 registros), agentes de inovação (6 registros). Outras dez pesquisas foram classificadas como "inovações no ensino". Cada pesquisa podia ser classificada em mais de uma das categorias, conforme sua adequação. A partir de agora, detalhamos os desdobramentos de cada uma dessas categorias. Optamos por apresentar a categoria "concepções de inovação" antes de todas as demais pôr a considerarmos mais abrangente. Nela o debate sobre inovação se dá em um nível teórico e/ou conceitual. As demais apresentam debates específicos, fortemente relacionados com diagnósticos do campo profissional.

\section{Concepções de Inovação}

Parte das pesquisas tem como fundamento a busca sobre como os diferentes atores compreendem o processo de inovação jornalística. Dos 33 trabalhos categorizados como "concepções de inovação", 19 tinham esse foco específico. São pesquisas que buscam explorar e descrever processos já em andamento, mapeando contribuições para o direcionamento das pesquisas conceituais, mas também buscam cartografar as compreensões dos agentes jornalísticos nos processos em desenvolvimento. A metodologia mais utilizada é a entrevista, seja com gestores e jornalistas que atuam diretamente nas redações (7 pesquisas), mas também especialistas do campo e líderes nos processos de gestão (4 pesquisas), leitores ( 2 pesquisas) e estudantes de jornalismo (1 pesquisa). Além destes, em um caso também são ouvidos profissionais de tecnologia que atuam em um laboratório de inovação do conglomerado de mídia Globo, no Brasil. São analisados, ainda, relatórios de inovação desenvolvidos por empresas consideradas como modelos de inovação (como o The New York Times) e os sites de startups em diferentes regiões do mundo, além de projetos de investigação sobre inovação (4 pesquisas) promovidos por organizações sociais ou entidades de pesquisa - como é o caso dos relatórios do Instituto Reuters em parceria com a Universidade de Oxford.

Além das entrevistas, outros sete trabalhos têm como fundamento o debate conceitual sobre inovação no jornalismo, buscando compreender sua origem e principais delineamentos, relacionando-os com um campo jornalístico em ampla transformação (6 pesquisas). Uma pesquisa que nos parece particularmente interessante, do pesquisador holandês Nico Drok, tem como perspectiva o debate sobre o componente cultural da inovação no jornalismo. Para o pesquisador,

Ainda que as pesquisas mostrem mudanças positivas, não há indicações claras de que uma inovação ambiciosa da cultura do jornalismo já tenha ocorrido. Em vez disso, novas e interessantes tecnologias ainda são usadas com muita frequência para alcançar fins tradicionais: jornalismo antigo em novas garrafas digitais. (DROK, 2018, s/p, tradução nossa ${ }^{2}$ ).

Em menor medida, mas ainda relacionados com a necessidade de compreensão da inovação no contexto jornalístico, mapeamos sete trabalhos que têm como foco o debate sobre metodologias para o estudo da inovação. Dois artigos com autoria do pesquisador espanhol José A. García-Avilés, dos quais um em coautoria, discutem o desenvolvimento de uma ferramenta teórico-metodológica para a análise e medição dos níveis de inovação específico para iniciativas midiáticas (GARCÍA-AVILÉS, 2017; GARCÍA-AVILÉS et al, 2018). Outros estudos sugerem diferentes perspectivas metodológicas para a investigação sobre inovação, como a semiótica discursiva (1 pesquisa), a pesquisa-ação (1 pesquisa), graus de inovação (1 pesquisa), análise de tendências (1 pesquisa) e o que Witschge, Deuze e Willemsen (2019) denominam "métodos artísticos" (1 pesquisa).

${ }^{2}$ No original: "Although research shows changes for the better, there are no clear-cut indications that an ambitious innovation of the culture of journalism has yet taken place. Instead, interesting new technologies are still too often used for achieving traditional ends: old journalism in new digital bottles". (DROK, 2018). 


\section{Inovação de Gestão}

Um dos principais eixos de investigação sobre inovação no jornalismo tem como foco o negócio, os modos de dar sustentabilidade para empresas jornalísticas de diferentes formatos e com distintas dimensões. O que significa inovar no negócio jornalístico e quais são as características centrais dos negócios inovadores correspondem a um total de 44 pesquisas no corpus analisado.

Entre os destaques, nosso mapeamento reconheceu um total 15 pesquisas em que os autores observam as práticas de empresas já consolidadas, buscando verificar as estratégias utilizadas por elas para a sustentabilidade do negócio de notícias. Essa categoria é a que conta com maior número de trabalhos neste eixo de análise, nos quais são descritas soluções variadas, como o investimento em estratégias de mobilidade para a produção e circulação de conteúdo, o uso de métricas e dados para a gestão dos negócios e até apontamentos de contribuições do design thinking ${ }^{3}$ para engajamento da audiência.

Alguns trabalhos têm como foco a análise da atuação de media labs, destacando que esses ambientes podem desenvolver soluções interessantes para os veículos jornalísticos. Ainda nas buscas pelas experiências inovadoras já em desenvolvimento no mercado jornalístico, encontramos dez pesquisas que tem como foco a observação sistematizada das características dos negócios de sucesso. Enquanto algumas dessas pesquisas vão tentar observar as particularidades de negócios de notícia que fizeram processos de migração do modelo impresso para o digital (4 pesquisas) ou em redes de televisão (3 pesquisas), outros pesquisadores buscaram mapear fatores e características de inovação em nativos digitais (3 pesquisas).

Outro eixo que nos pareceu relevante tem como foco a observação específica das startups jornalísticas. Do total de dez trabalhos categorizados em nosso estado da arte a partir desse padrão, duas pesquisas observam as características de diferentes modelos de negócio para startups de notícias, enquanto outras oito pesquisas têm como foco a descrição das experiências de desenvolvimento de startups em diferentes regiões do mundo - como América Latina, Brasil, China, África do Sul e Índia.

Os pesquisadores também se detêm na observação de lógicas de financiamento para publicações de nicho ou aquelas desenvolvidas em contextos muito particulares. São cinco as pesquisas classificadas neste eixo. Entre os dados mais relevantes, citamos o interesse em debater a sustentabilidade de jornais regionais

${ }^{3}$ Design thinking pode ser descrito como uma abordagem para o desenvolvimento de produtos e serviços que utiliza as ferramentas do design (inspiração, idealização, implementação) no processo de criação e solução dos problemas. Seu foco está em “[...] estabelecer correspondência entre as necessidades humanas com os recursos técnicos disponíveis considerando as restrições práticas dos negócios (BROWN, 2018, s/p).

${ }^{4}$ Modelo de financiamento de projetos baseado na obtenção de capital a partir da agregação de múltiplos financiadores individuais interessados na iniciativa. e locais, com conteúdo de nicho (jornalismo ambiental), aqueles caracterizados como jornalismo independente e, em um caso, modelos de financiamento para veículos de jornalismo que exercem suas atividades em contextos políticos autoritários. Em todos os casos, a inovação é estabelecida pelos pesquisadores como vetor para a operacionalização dos negócios.

Há ainda uma última categoria enquadrada no eixo de investigação sobre inovações de gestão. Nela reconhecemos cinco publicações que têm como objetivo propor soluções para o negócio jornalístico, a partir do cruzamento entre teoria e prática. Esses estudos não focam em uma experiência prática específica, mas partem do conhecimento teórico acumulado para sugerir opções de ação para empresas jornalísticas. Nesse contexto, destacam-se propostas de modelo de negócio - com base na curadoria de conteúdo, no uso de agregadores de conteúdo ou de crowdfunding 4 , e até mesmo sem financiamento externo - mas também propostas que sugerem o investimento em políticas de mídia que favoreçam o desenvolvimento do negócio de notícias.

\section{Inovação de Processo}

As inovações de processos, ainda que tenham um potencial relevante para a configuração de inovações no campo jornalístico, são objetos de investigação dos 
pesquisadores em poucos estudos. Em nossa análise, aparecem em apenas $16 \mathrm{pu}-$ blicações. Essas investigações são mais dispendiosas para os analistas, porque em geral exigirão a imersão nas rotinas de trabalho das redações.

Reconhecemos quatro dinâmicas particulares de pesquisas que tem como foco as inovações de processos. A primeira delas, que tem mais destaque entre os estudiosos, é aquela que busca compreender reorganizações nos fluxos de trabalho (10 pesquisas). São exemplos dessas investigações aquelas que analisam as reconfigurações das rotinas de produção por conta dos processos de convergência midiática ou pela implementação de uma rotina temporal baseada no imediato (com a migração das lógicas do impresso para o digital).

Da mesma forma, quando um novo formato narrativo passa a ser explorado na redação, como a produção de vídeos em 360 graus, por exemplo, existirá a necessidade de reorganização dos fluxos de trabalho. O mesmo acontece com redações que optam pela inserção de ferramentas de automação ou pelo uso de métricas sobre a audiência para direcionar o trabalho das redações - nos dois casos passa a haver a necessidade de negociação das rotinas pré-estabelecidas, de modo a que esses processos sejam incluídos nas dinâmicas de trabalho. $\mathrm{O}$ jornalismo de dados, que tem suas metodologias de trabalho mais difundidas no contexto brasileiro, aparece destacado em duas pesquisas que tentam compreender suas implicações nas rotinas de trabalho dos jornalistas.

Outras duas pesquisas discutem a gestão de processos: como o uso do conceito de Supply-side Reform ${ }^{5}$ para a otimização de rotinas de estruturação da grade de programação de canais de televisão e o desenvolvimento de um sistema informático para a gestão de produção compartilhada de notícias nas redações. A participação dos leitores nos processos de produção também foi notada como um fenômeno passível de exigir adaptações das redações, visto que essa produção compartilhada exige a reorganização das rotinas dos jornalistas.

\section{Inovação de Produtos}

O desenvolvimento de novos produtos é outro relevante aspecto para a análise de inovação no jornalismo. A maioria dos pesquisadores que se detém a analisar propostas editoriais ou narrativas inovadoras, entretanto, não os faz a partir das lógicas dos estudos sobre inovação. Por conta disso, em nossa análise essa categoria contou com apenas 17 registros. Essa constatação destaca, de modo particular, a relevância de consolidação do debate teórico sobre inovação no jornalismo, que poderia favorecer não apenas o mapeamento de iniciativas já em curso, mas também tem o potencial de agregar camadas de complexidade para pesquisas que venham a propor novos produtos.

Em nossa análise, cinco das pesquisas categorizadas como "inovação de produto" dizem respeito à descrição de formatos considerados inovadores para o jornalismo, como os newsgames ${ }^{6}$ e os vídeos em realidade virtual, as narrativas em long form ${ }^{7}$ e os podcasts. Da mesma forma, outros quatro trabalhos têm como fundamento a proposição de metodologias para a implementação de novos formatos na rotina das redações - entre eles, métodos para a produção de newsgames e vídeos em realidade virtual, o uso de storytelling ${ }^{8}$ e de técnicas de design thinking para a construção narrativa das histórias jornalísticas.

Neste eixo de análise, como nos outros casos, os pesquisadores também buscam referências na descrição de produtos já em circulação, buscando compreender de que modos podem ser considerados inovadores. Isso aconteceu seis vezes em nossa pesquisa de estado da arte. São trabalhos que investigam as características de produções noticiosas para defini-los como transmídia, mas também a descrição de formatos, ferramentas e protótipos inovadores.

${ }^{5}$ Termo recorrente nos estudos sobre macroeconomia, as reformas supply-side (do lado da oferta) têm como objetivo otimizar o fornecimento de produtos e serviços e, assim, melhorar a produtividade. Seu fundamento central está no controle dos níveis de estoque, aspecto que exige mais do capital da empresa, que passa a operar sob demanda.

${ }^{6}$ Narrativas jornalísticas estruturadas a partir da linguagem de jogos eletrônicos/digitais.

${ }^{7}$ Narrativas jornalísticas estruturadas a partir de artigos longos e com ampla utilização de multimídia.

${ }^{8}$ Storytelling é um conjunto de técnicas narrativas baseadas em roteiros. 


\section{Agentes de Inovação}

Decidimos pela apresentação de uma última categoria que, ainda que represente um percentual menor do corpus de análise, nos parece particularmente relevante quando relacionada com o contexto teórico dos estudos sobre inovação em outras áreas do conhecimento. É a que definimos como "agentes de inovação". O debate sobre os agentes é importante porque as dinâmicas econômicas e políticas de inovação são descritas na literatura especializada a partir da correlação entre muitos agentes - a exemplo das lógicas de Pesquisa e Desenvolvimento (P\&D), que envolvem empresas privadas e centros de pesquisa na formação de mão de obra qualificada e no desenvolvimento de inovação aplicada às demandas do mercado.

Em nossa análise, seis trabalhos podem ser categorizados a partir do debate sobre agentes de inovação. Em um caso, o debate é centrado no que os autores chamam de "organizações auxiliares" - associações profissionais, centros de treinamento, fundações, laboratórios - e seu efeito nas dinâmicas da inovação jornalística (LOWREY, SHERRILL, BROUSSARD, 2019). Outro trabalho discute a presença de interlopers $^{9}$ e intraloper $^{10}$, atores não-jornalistas que passam a atuar na produção jornalística, inclusive dentro das redações (HOLTON, BELAIR-GAGNON, 2018).

Além destes, as lideranças são tematizadas em três trabalhos como importantes agentes de inovação - em um caso, a análise se dá a partir da questão de gênero, tensionando a liderança de mulheres em startups de notícias; em outro caso, a reflexão é mais abrangente, pensando sobre o papel dos líderes institucionais na assimilação de inovações em organizações jornalísticas; por fim, uma das pesquisas relaciona à competência de inovar ao contexto de experimentação das TVs universitárias.

Nossa análise ainda reconheceu um último eixo de pesquisas, que pensa sobre o processo de inovação no ensino de jornalismo. Isso acontece a partir de duas perspectivas: modos inovadores de ensinar jornalismo e ensino de inovação nos cursos de graduação. Decidimos por não destacar essa categoria por compreendermos que ela se insere em um contexto particular de debates sobre o ensino de jornalismo e fogem do escopo deste artigo. Ainda assim, as concepções sobre inovação no ensino e ensino de inovação são relevantes no debate mais amplo da institucionalização do conceito de inovação no jornalismo e merecem desdobramento

${ }^{9} \mathrm{O}$ termo interlopers descreve atores que posicionam seu trabalho como jornalismo, ainda que sofram críticas fortes de agentes historicamente reconhecidos como jornalistas ou integrantes da instituição jornalística. Esses “intrusos" podem ser implícitos ou explícitos (HOLTON, BELAIR-GAGNON, 2018)

${ }^{10} \mathrm{O}$ termo "intralopers" descreve indivíduos que trabalham indivíduos que atuam em organizações jornalísticas sem advogar a si próprios um papel ou rótulo de jornalista, eles podem ser treinados em jornalismo ou versados na profissão (HOLTON, BELAIR-GAGNON, 2018). em pesquisas futuras. Encontramos um total de dez trabalhos nesta categorização. São descritas experiências de produção experimental em jornalismo em contextos de convergência e inovação, o ensino de empreendedorismo e, em um caso, os estágios de desenvolvimento dos cursos de jornalismo pela perspectiva da inovação.

\section{Considerações finais}

Este trabalho teve como propósito apresentar um mapeamento do estado da arte sobre jornalismo e inovação, tendo como foco as pesquisas desenvolvidas entre 2017 e 2019, quando identificamos um total de cinco eixos temáticos, sendo eles: concepções de inovação, inovação de gestão, inovação de processo, inovação de produto, agentes de inovação. Além de mapear as principais temáticas discutidas pelo campo, também nos interessava mapear os autores e publicações que têm se dedicado a debater a questão da inovação no contexto do jornalismo. Nossa pretensão era tentar descobrir referências entre os pesquisadores ou em determinadas regiões do mundo, mas encontramos uma grande fragmentação. Em nosso corpus, apenas 13 autores aparecem com dois ou mais textos publicados no período analisado, o que nos mostra que ainda é difícil encontrar referências consolidadas sobre o tema.

O conceito de inovação tem sido relacionado aos estudos de jornalismo, mas nos parece relevante salientar que sua emergência é destacada, em grande medida, 
de forma contextual. Parece saliente que o Jornalismo está passando por processos complexos de transformação e que existe a necessidade de reformulações em concepções, técnicas e processos. Entretanto, se essas transformações podem ser consideradas como inovações é ainda uma questão menos corrente. As pesquisas, em sua maioria, ainda buscam descrever iniciativas de sucesso na tentativa compreender os motivos do êxito, mas o debate conceitual sobre a inovação e sua capacidade de geração de impacto no campo jornalístico - seja a partir do mapeamento e da mediação dos graus de inovação já em processo no mercado, seja na promoção de pesquisas aplicadas que se convertam em contribuições substanciais aos processos de inovação - ainda é tímido.

Nossa pesquisa demonstrou a diversidade temática inerente ao estudo sobre inovação e aponta para o potencial do desenvolvimento do conceito nos estudos de jornalismo. Entre os avanços necessários, nos parece relevante o debate sobre os sistemas de inovação, envolvendo o jornalismo em nível organizacional (de gestão, de investimentos, de processos) e em nível institucional (de valores, de deontologia). Mais do que explorar e descrever iniciativas, processos, técnicas e artefatos inovadores, nos parece premente um debate sobre as relações entre o jornalismo e os financiadores de inovação. "Um conceito não é somente o indicador dos conteúdos compreendidos por ele, é também seu fator. Um conceito abre determinados horizontes, ao mesmo tempo em que atua como limitador das experiências possíveis e das teorias" (KOSELLECK, 2006, p. 109-110). Neste sentido, a emergência recente da inovação como um conceito caro ao jornalismo inscreve não apenas um interesse empírico imediato, mas também um horizonte de expectativas que indicam o desenvolvimento de um tipo específico de perguntas e de uma agenda específica de investigações.

\section{Referências}

ADGHIRNI, Zélia Leal. Mudanças estruturais no jornalismo: travessia de uma zona de turbulência. In: ADGHIRNI, Zélia Leal; PEREIRA, Fábio Henrique; MOURA, Dione Oliveira (Orgs.). Jornalismo e sociedade: teorias e metodologias. Florianópolis: Editora Insular, 2012, p. 61-79.

ANDERSON, C.W; BELL, Emily; SHIRKY, Clay. Post-Industrial Journalism Adapting to the Present. New York: Tow Center, 2012. Relatório. Disponível em: http://bit.ly/postindjorn. Acesso em: 17 maio 2020.

BITTENCOURT, Maria Clara Aquino. Jornalismo, inovação e empreendedorismo: questões sobre modelos de negócio em contexto de crise. Líbero, São Paulo, v. 21, n. 41, p. 74-87, jan./jun. 2018.

BROWN, Tim. Design Thinking: uma metodologia poderosa para decretar o fim das velhas ideias. Rio de Janeiro: Alta Books, 2018.

CANAVILHAS, João et al. Jornalistas e tecnoatores: a negociação de culturas profissionais em redações on-line. Revista Famecos: mídia, cultura e tecnologia, v. 23, n. 3, 2016.

COSTA, Andriolli Brites da. Jornalismo robô e jornalismo robotizado. Mudanças estruturais a partir da interação mediada por dispositivos. In: $14^{\circ}$ Encontro Nacional de Pesquisadores em Jornalismo, 2016, Palhoça - SC. Anais... São Paulo: SBPJor, 2016. 
CREECH, B.; NADLER, A. M. Post-Industrial Fog: Reconsidering innovation in visions of journalism's future. In: Journalism, v. 19, Issue 2, p. 182-199. 2017. Disponível em: https://doi. org/10.1177/1464884916689573. Acesso em: 11 jun. 2020.

DE MATEO, Rosario; BERGÉS, Laura; GARNATXE, Anna. Crisis, what crisis? The media: business and journalism in times of crisis. TripleC, v. 8, n. 2, p. 251-274, 2010.

DROK, Nico. Towards a broader concept of innovation in journalism. Questions de Communication, v. 34 , n. 02 , p. 271-284, 2018. DOI: 0.4000/questionsdecommunication.15999.

ELDRIDGE II, Scott. Repairing a fractured field: Dynamics of collaboration, normalization and appropriation at intersections of newswork. Journal of Applied Journalism \& Media Studies. v. 7, n. 3, p. 541-559, 2018. DOI: 10.1386/ ajms.7.3.541_1.

FLORES, Ana Marta. Jornalismo de inovação: os Estudos de Tendências como ferramenta de pesquisa. Florianópolis: UFSC, 2019, 237 p. (Tese de Doutorado). Programa de Pós-Graduação em Jornalismo - Universidade Federal de Santa Catarina. (Orientação: Raquel R. Longhi).

FRANCISCATO, Carlos Eduardo. A fabricação do presente. São Cristóvão: Editora UFS, 2005.

FRANCISCATO, Carlos Eduardo. Uma proposta de incorporação dos estudos sobre inovação nas pesquisas em jornalismo. Estudos em Jornalismo e Mídia, Florianópolis, Ano VII, n. 1, p. 8-18, 2010.

FRANCISCATO, Carlos Eduardo. Inovações tecnológicas e transformações no jornalismo com as redes digitais. Geintec, São Cristóvao, v. 4, n. 4, p. 1329-1339, 2014.

GARCÍA-AVILÉS, José-Alberto. Identifying Innovation. How to grasp the chance of change-some lessons from Spain. Journalism Report V. Innovation and transition, p. 35-48. Viena: Facultas, 2017.

GARCÍA-AVILÉS, José A.; CARVAJAL-PRIETO, Miguel; LARA-GONZÁLEZ, Alicia De.; ARIAS-ROBLES, Félix. Developing an index of media innovation in a national market: The case of Spain. Journalism studies, v. 19, n. 1, p. 25-42, 2018.

GROHMANN, Rafael. Inovação como fórmula discursiva convocatória para as práticas jornalísticas: sentidos mobilizados por textos do Observatório da Imprensa. In: Congresso Brasileiro de Ciências da Comunicação, 39, 2016, São Paulo - SP. Anais... São Paulo: Sociedade Brasileira de Estudos Interdisciplinares da Comunicação (Intercom), 2016.

GROHMANN, Rafael. Inovação como Fórmula Discursiva Convocatória Para as Práticas Jornalísticas: sentidos mobilizados por textos do Observatório da Imprensa. Contemporânea, Salvador, v. 15, n. 1, p. 207-226, 2017.

GROHMANN, Rafael; ROXO, Michelle. Os discursos sobre o jornalista-empreendedor em sites especializados na cobertura do campo profissional. Contemporânea, Salvador, v. 13, n. 2, p. 471-486, 2015. 
HOLTON, Avery E.; BELAIR-GAGNON, Valerie. Strangers to the Game? Interlopers, Intralopers and Shifting News Production. Media and Communication, v. 6, n. 4 , p. $70-78,2018$.

KOSELLECK, Reinhart. Futuro passado: contribuições à semântica dos tempos históricos. Rio de Janeiro: Contraponto / Ed. PUC-Rio, 2006.

LONGHI, Raquel Ritter; FLORES, Ana Marta. Narrativas webjornalísticas como elemento de inovação: casos de Al Jazeera, Folha de S. Paulo, The Guardian, The New York Times e The Washington Post. Intercom: Revista Brasileira de Ciências da Comunicação, v. 40, n. 1, p. 21-40, 2017.

LOWREY, Wilson; SHERRILL, Lindsey; BROUSSARD, Ryan. Field and ecology approaches to journalism innovation: the role of ancillary organizations. Journalism Studies, v. 20, n. 15, p. 2131-2149, 2019.

OECD/EUROSTAT. Oslo Manual 2018: Guidelines for Collecting, Reporting and Using Data on Innovation - 4th Edition, The Measurement of Scientific, Technological and Innovation Activities. Luxembourg: OECD Publishing / Paris: Eurostat, 2018.

PEREIRA, Fábio Henrique; ADGHIRNI, Zélia Leal. O jornalismo em tempo de mudanças estruturais. Intexto, Porto Alegre: UFRGS, v. 1. n. 4. p. 38-57, jan./jun. 2011.

RODIGUES, Léo Peixoto. A ciência pós-determinista, supradisciplinar e transparadigmática: reacendendo o debate sobre teoria, analogia e conceito. Revista Trans/Form/Ação, v. 43, n. 01, p. 151-172, 2020. DOI: /10.1590/0101-3173.2020. v43n1.09.p151.

SAAD, E. Inovação e empresas informativas: aliados, inimigos ou em permanente estado de "discussão da relação"? Parágrafo, v. 2, n. 2, p. 72-87, 2016.

SALAVERRÍA, Ramón. Convergencia de los medios. Revista Latinoamericana de Comunicación (CHASQUI), Equador, n. 81, p. 32-39. 2003. Disponível em: https:// www.redalyc.org/pdf/160/16008105.pdf. Acesso em: 23 out. 2020.

SCHUMPETER, Joseph Alois. Teoria do Desenvolvimento Econômico: uma investigação sobre lucros, capital, crédito, juro e o ciclo econômico. São Paulo: Nova Cultural, 1985.

TAVARES, Camilla Quesada. O que se sabe sobre a crise do jornalismo? Uma revisão da literatura internacional. $15^{\circ}$ Encontro Nacional de Pesquisadores em Jornalismo, 2017, Universidade de São Paulo. Anais... São Paulo: SBPJor, 2017.

WITSCHGE, Tamara; DEUZE, Mark; WILLEMSEN, Sofie. Creativity in (digital) journalism studies: Broadening our perspective on journalism practice. Digital Journalism, v. 7, n. 7, p. 972-979, 2019. 